\title{
LEGAL DOCUMENTS IN ANCIENT SOCIETIES
}

1. THE LETTER

Rome, 28-30.9.2008

2. TRANSACTION COSTS IN THE ANCIENT WORLD Washington DC, 27-28.7.2009

3. IDENTIFIERS AND IDENTIFICATION METHODS Leuven-Brussels, 23-25.9.2010

4. ARCHIVES AND ARCHIVAL DOCUMENTS IN ANCIENT SOCIETIES Trieste, 30.9-1.10.2011

5. SALE AND COMMUNITY Budapest, 6-7.10.2012

6. ANCIENT GUARDIANSHIP Jerusalem, 3-5.11.2013

7. THE LOAN CONTRACT IN ANCIENT SOCIETIES Paris, 27-29.08.2015 